\title{
Using standard keywords in publications to facilitate updates of new fungal taxonomic names
}

\author{
Conrad L. Schoch ${ }^{1}$, M. Catherine Aime 2 , Wilhelm de Beer ${ }^{3}$, Pedro W. Crous ${ }^{4}$, Kevin D. Hyde ${ }^{5}$, Lyubomir \\ Penev $^{6}$, Keith A. Seifert ${ }^{7}$, Marc Stadler ${ }^{8}$, Ning Zhang, and Andrew N. Miller ${ }^{10}$
}

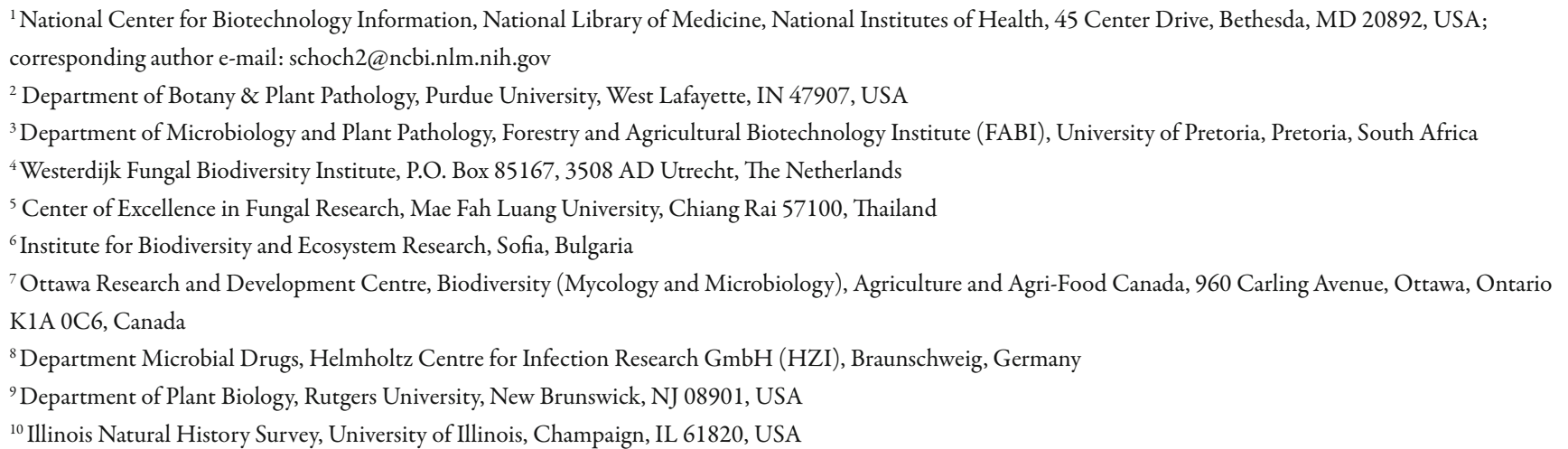

Abstract: The combination of manual curation and the reliance on updates from submitters to the public sequence databases is currently inefficient and impedes the comprehensive and timely release of records with new taxonomic names. This should be improved by making several steps during data release more efficient. This article focuses on one such step by proposing a standard way for publications to flag papers with novel taxonomic information. As a result, the potential for automated searches of publication aggregators are improved, as well as the accurate curation of taxonomic information.

Key words: Data curation, NCBI Taxonomy, Novel taxa, Publication standards.

An abundance of online sources and databases are available to the modern mycologist. Nomenclature and taxonomic information is easily accessed via resources such as MycoBank and Index Fungorum, in addition to numerous smaller databases focused on functional or taxonomic groups (Yahr et al. 2016). Computational analyses can be performed by accessing molecular data stored by the International Sequence Database Consortium (INSDC) that includes GenBank at the National Center for Biotechnology Information (NCBI), DNA database for Japan (DDBJ) and the European Nucleotide Archive (ENA). However, the accuracy of taxonomic names associated with these records has remained a concern for many biologists, and mycologists have long been vocal in this regard (Nilsson et al. 2006, Bidartondo et al. 2008). Because the NCBI Taxonomy database acts as a central organizing hub of the databases of the INSDC it fulfils a crucial role in taxonomic labelling of sequence records (Federhen 2012). Recent improvements such as the ability to track type material, ability to link out to third party databases with additional information (Federhen 2015) and the addition of curated markers (Schoch et al. 2014) have been steps toward resolving this problem.
Additionally, the Biocollection Database at NCBI (https://www.ncbi.nlm.nih. gov/biocollections/) now provides the ability to structure submissions to account for standardized repository information. However, many molecular sequence submissions to the public databases still have inadequate and incomplete metadata relating to samples (isolate, strain, bio material, culture collection or specimen voucher). The result is additional complications for any attempts at improved curation.

The current system of NCBI curation requires submitters to be diligent in updating their information after publication. When a provisional name is evident it is added with a temporary label and an "unpublished name" property in the NCBI Taxonomy database - meaning that it will not be displayed publicly but its associated records can be found in a direct text search. The eventual release of these names upon valid publication are primarily the responsibility of the author. Authors are therefore asked to update the database when their sequence data is published and their newly proposed taxonomic names validated. However, this step is often neglected. Taxonomic curators do make updates independently but this is inefficient and a comprehensive scanning of all taxonomic literature is still impossible. This increasing problem is illustrated in Fig. 1. All unpublished names in the NCBI Taxonomy since 2009 are indicated (when the unpublished name type was first introduced for provisional names). Over recent years, there appears to be an acceleration in the number of all unreleased taxonomic names. This effect is mirrored in fungal names with a small increase in the percentage from 2009 (25-30\%).

It remains a concern that despite having multiple electronic resources available, several new names that were proposed with sequence data still elude the public domain. This is not unique to Fungi (Uetz \& Garg 2017), but with judicious use of several important sources of available information the process of the public release and propagation of new fungal taxonomic names can be much improved. This can be done by improving information along all the required author submission steps for publication and propagation, to whit: taxonomic name registration, public sequence deposit and publication. Firstly, we urge submitters to revisit their data after publication to ensure the publication details are updated correctly. Secondly, information sharing between databases should be 
Unpublished names in NCBI Taxonomy database

12000

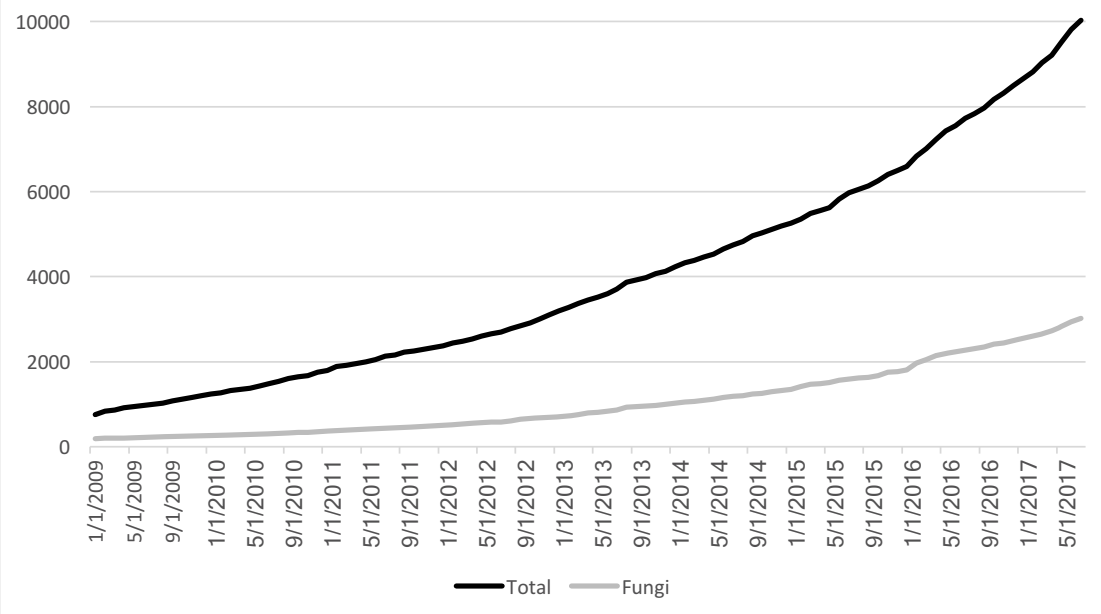

Fig. 1. Increase in unpublished names in NCBI Taxonomy for each month from first application of this name type over the period 1 January 2009 to 1 June 2017. The total number of all taxonomic names and fungal names only are indicated.

improved. This includes the synchronization between the name registries as well as the use of third party managed links, such as LinkOut in the NCBI databases (Federhen 2012). Finally, newly published taxonomic information should be more easily discoverable, to lower the burden of manual curation.

The 25 journals with the most taxonomy identification numbers (taxids) added to INSDC over the last five years are indicated in Table 1. These taxids are used to track unique names in the NCBI Taxonomy database and are also used by INSDC partners and other databases. In the second column, the total number of new species described in each journal since 2012 is indicated. The disparity between these numbers indicate that either a species was not annotated correctly in NCBI Taxonomy, or no sequence data was associated with it. This set of 25 journals represents $88 \%$ of all deposited taxids from newly described species and $80 \%$ of all new species published over the last five years. If one only considers journals with a PubMed presence the equivalent numbers are $34 \%$ and $55 \%$. Another important number in this table is the species still tagged with an unpublished name type which represents $6 \%$ of the total published names over this period. While these unpublished names can now be verified and publicized as part of the NCBI taxonomic curation, an unknown number of species were not flagged with unpublished name types before publication.

Many fungal journals already provide extensive information on new taxa in the abstract either as text or under specific heading, such as "Taxonomic novelties". Often new names are documented in the title of a paper. This is commendable and very effective. However, this is not done consistently across journals. In order to expand the ability to detect taxonomic novelties automatically and reliably across many different journals we propose a simplified, agreed upon standard keyword that could clearly be used to flag fungal publications with novel taxonomic information. This will only improve taxonomic curation of the public sequence databases and provide benefits to third party users and external resources. This standard should be improved and expanded as the need arises.

This simple proposal arose out of discussions in a working group set up by the International Commission on the Taxonomy of Fungi (ICTF; http://www. fungaltaxonomy.org/) and the contributors to this paper include several current or former editors of major fungal taxonomic journals. A small set of keywords are proposed that can be flagged in PubMed and other aggregators of literature: $\mathbf{x}$ new taxa (With $x$ denoting the number of taxa as a digit and "taxa" including all taxa: species, genera, etc.) OR in the case of one new taxon: 1 new taxon.
In the case of additional typifications, not related to new species: $\mathbf{x}$ new typifications / 1 new typification.

The keywords can be associated with optional footnotes (e.g. new taxa ${ }^{1}$ ). In the footnote, all the actual new taxa can be spelled out separated by semi colons. This can provide a way to remain within word limitations in an abstract; and with a single keyword instead of multiples that indicate rank, key word limits would not be squandered.

Example:

Key words: 3 new taxa ${ }^{1}, 1$ new typification ${ }^{2}$ ${ }^{1}$ Exemplum gen. nov.; Exemplum secundum sp. nov.; Exemplum unum comb. nov.

${ }^{2}$ Epitype proposed for Exemplum unum

The participating journals commit to add the following text on a visible place in their Instructions to Author guidelines: "This journal requires that, in case the manuscript contains descriptions of new taxa of any taxonomic rank, to put a keyword " $\mathrm{X}$ new taxa" where the $\mathrm{X}$ is a digit indicating the number of new taxa in the manuscript. In the case of a single taxon it should read "1 new taxon". We strongly recommend to add the list of new taxon names according to journal specifications. This feature will help timely recording of your new taxa in INSDC and other relevant aggregators of taxonomic information". Where additional typifications (lectotypes, neotypes, epitypes etc.) are proposed we propose listing those under a separate keyword, "X new typifications" under the same conditions as above.

In addition, participating journals are urged to promote this new feature to their users and to introduce the respective changes in their routine editorial policies and workflows by January 2018.

\section{CONCLUSIONS}

The challenge discussed here exists within the larger context of improving the timely public release of all published data. Recently the development of Wide-Open, a programmatic approach using text mining to detect published but unreleased data was described (Grechkin et al. 2017). The first run of this approach focused on records in the Gene Expression Omnibus (GEO) repository and the Sequence Read Archive (SRA) at NCBI. The process of scanning PubMed articles for unique identifiers related to these resources found several 
Table 1. The top 25 mycological journals publishing new species ranked by newly assigned NCBI taxids for the five years 1 January 2012 to 1 June 2017.

\begin{tabular}{|c|c|c|c|c|c|c|c|}
\hline Publication & $\begin{array}{l}\text { Species with } \\
\text { new taxids }\end{array}$ & $\begin{array}{l}\text { Total new } \\
\text { species } \\
\text { published }\end{array}$ & $\begin{array}{l}\text { Unpublished } \\
\text { names in NCBI } \\
\text { Taxonomy }\end{array}$ & $\begin{array}{l}\text { h5-index } \\
\text { (GOOGLE) }\end{array}$ & $\begin{array}{l}\text { h5-median } \\
\text { (GOOGLE) }\end{array}$ & $\begin{array}{l}\text { PubMed } \\
\text { ID (PMID) }\end{array}$ & PubMed Status \\
\hline Studies in Mycology & 1301 & 1679 & 29 & $\mathrm{~N} / \mathrm{A}$ & $\mathrm{N} / \mathrm{A}$ & 8411984 & Indexed \\
\hline Persoonia & 1236 & 1662 & 54 & 24 & 35 & $19540520 \mathrm{R}$ & Indexed \\
\hline Fungal Diversity & 1126 & 1853 & 175 & 45 & 61 & 100955518 & $\begin{array}{l}\text { Selected } \\
\text { citations only }\end{array}$ \\
\hline Mycologia & 841 & 1263 & 126 & 32 & 44 & 400764 & Indexed \\
\hline Mycological Progress & 632 & 999 & 104 & 20 & 23 & 101136371 & $\begin{array}{l}\text { Selected } \\
\text { citations only }\end{array}$ \\
\hline Phytotaxa & 417 & 1077 & 84 & 19 & 28 & 101517955 & $\begin{array}{l}\text { Not currently } \\
\text { indexed }\end{array}$ \\
\hline Mycotaxon & 307 & 1032 & 44 & 17 & 27 & 9876348 & $\begin{array}{l}\text { Not currently } \\
\text { indexed }\end{array}$ \\
\hline Fungal Biology & 268 & 356 & 30 & 28 & 37 & 101524465 & Indexed \\
\hline The Lichenologist & 234 & 938 & 45 & 18 & 24 & 100955368 & $\begin{array}{l}\text { Selected } \\
\text { citations only }\end{array}$ \\
\hline IMA Fungus & 206 & 671 & 14 & 19 & 37 & 101557546 & Indexed \\
\hline Nordic Journal of Botany & 171 & 227 & 2 & 14 & 25 & 9886922 & $\begin{array}{l}\text { Not currently } \\
\text { indexed }\end{array}$ \\
\hline Mycoscience & 159 & 309 & 38 & 17 & 22 & 9890476 & $\begin{array}{l}\text { Selected } \\
\text { citations only }\end{array}$ \\
\hline Index Fungorum & 156 & 359 & 4 & N/A & $\mathrm{N} / \mathrm{A}$ & 101615729 & $\begin{array}{l}\text { Not currently } \\
\text { indexed }\end{array}$ \\
\hline Cryptogamie Mycologie & 149 & 304 & 14 & 12 & 17 & 100961513 & $\begin{array}{l}\text { Not currently } \\
\text { indexed }\end{array}$ \\
\hline IJSEM & 129 & 208 & 12 & 40 & 58 & 100899600 & Indexed \\
\hline Mycosphere & 120 & 429 & 21 & 13 & 21 & 101534483 & $\begin{array}{l}\text { Not currently } \\
\text { indexed }\end{array}$ \\
\hline Antonie van Leeuwenhoek & 116 & 170 & 10 & 29 & 41 & 372625 & Indexed \\
\hline PloS ONE & 106 & 183 & 2 & 166 & 215 & 101285081 & Indexed \\
\hline Ferrantia & 104 & 326 & 104 & N/A & N/A & $\mathrm{N} / \mathrm{A}$ & $\begin{array}{l}\text { Not currently } \\
\text { indexed }\end{array}$ \\
\hline Acta Botanica Hungarica & 85 & 250 & 1 & 9 & 13 & 101582241 & $\begin{array}{l}\text { Not currently } \\
\text { indexed }\end{array}$ \\
\hline Sydowia & 84 & 186 & 5 & 8 & 9 & 100955200 & $\begin{array}{l}\text { Not currently } \\
\text { indexed }\end{array}$ \\
\hline Nova Hedwigia & 72 & 250 & 20 & 14 & 23 & 101317353 & $\begin{array}{l}\text { Not currently } \\
\text { indexed }\end{array}$ \\
\hline CBS Biodiversity Series & 63 & 266 & 2 & $\mathrm{~N} / \mathrm{A}$ & $\mathrm{N} / \mathrm{A}$ & $\mathrm{N} / \mathrm{A}$ & $\begin{array}{l}\text { Not currently } \\
\text { indexed }\end{array}$ \\
\hline The Bryologist & 55 & 189 & 4 & 13 & 14 & 100955480 & $\begin{array}{l}\text { Selected } \\
\text { citations only }\end{array}$ \\
\hline Mycokeys & 48 & 140 & 13 & N/A & N/A & 101569696 & Indexed \\
\hline
\end{tabular}

overdue datasets that could be released. This elicited a positive response from curators at $\mathrm{NCBI}$ and resulted in the accelerated release of several records (Williams 2017), but this can and should be expanded to other data sets. Another promising new development in this direction is automated workflows for text mining of taxonomic journals providing alert services on new taxa and other semantically recognizable sub-article elements (e.g. taxon treatments, images, occurrence records, identification keys) on the day of publication. Such a service is currently being developed through the
RDF-based Open Biodiversity Knowledge Management System (OpenBiodiv; Senderov et al. 2017). This system will provide automated machine-readable information in RDF to be harvested by aggregators such as GBIF, Catalogue of Life, NCBI, and others. 
We focused on a very particular problem in this paper: the validation of unpublished names attached to the newly released sequence data. The curation process continues to depend on inefficient workflows that requires submitters to provide updates after publication. While improvements can and will be made, important opportunities exist to utilize information within abstracts in PubMed and other database aggregators. Fungal biology has become reliant on a public collection of nucleotide sequence data to compare and improve the cataloguing of diversity. This simple proposal, if widely applied, can significantly improve the synchronization of the release of new taxonomic data in publications and public databases, aiding discovery and data integration in biology

\section{ACKNOWLEDGEMENTS}

This paper resulted from discussions in Group 5 under the auspices of the International Commission on the Taxonomy of Fungi (ICTF). The Intramural Research Program of National Institutes of Health, National Library of Medicine is also acknowledged.
We are grateful to Stacy Ciufo (NCBI) for her help in preparing the figure and table.

\section{REFERENCES}

Bidartondo MI, Bruns TD, Blackwell, M, Edwards I, Taylor AFS, et al. (2008) Preserving accuracy in GenBank. Science 319: 1616.

Federhen S (2012) The NCBI Taxonomy database. Nucleic Acids Research 40: D136-D143.

Federhen S (2015) Type material in the NCBI Taxonomy Database. Nucleic Acids Research 43: D1086-D1098.

Grechkin M, Poon H, Howe B (2017) Wide-Open: accelerating public data release by automating detection of overdue datasets. PLoS Biology 15: e2002477.

Nilsson RH, Ryberg M, Kristiansson E, Abarenkov $\mathrm{K}$, Larsson KH, et al. (2006) Taxonomic reliability of DNA sequences in public sequence databases: a fungal perspective. PLOS ONE 1: e59.

Schoch CL, Robbertse B, Robert V, Vu D, Cardinali G, et al. (2014) Finding needles in haystacks: linking scientific names, reference specimens and molecular data for Fungi. Database: bau061.
Senderov V, Georgiev T, Agosti D, Catapano T, Sautter G, et al. (2017) OpenBiodiv: an implementaion of a semantic system running on top of the biodiversity knowledge graph. Proceedings of TDWG 1: e20084.

Uetz P, Garg A (2017) Molecular taxonomy: species disconnected from DNA sequences. Nature 545: 412.

Williams R (2017) Making public data public. The Scientist Magazine June 8 https://www.thescientist.com/?articles.view/articleNo/49629/ title/Making-Public-Data-Public/.

Yahr R, Schoch CL, Dentinger BT (2016) Scaling up discovery of hidden diversity in fungi: impacts of barcoding approaches. Philosophical Transactions of the Royal Society of London, Series B, Biological Sciences 371: 20150336. 